\title{
Antagonistic potential of some phosphate solubilizing fungi against some phyto-pathogenic fungi
}

\author{
Siada H. Nasr ${ }^{*}$ (D, A. S. M. Mousa, M. M. Yasser and M. A. Marzouk
}

\begin{abstract}
Background: Little phosphorus availability in soil is one of the major forces for crop production. Phosphate solubilizing fungi enhance available phosphorus from soils and contribute to achieve the plants phosphorus requirement. Phosphate solubilizing fungi are important component of soil microbiota and play an essential role in the biogeochemical cycling of phosphorus in natural ecosystems.

Results: The study tested the potential of the isolated phosphate solubilizing fungi to inhibit the growth of Alternaria alternata, Fusarium solani, Geotrichum candidum, Rhizoctonia solani and Sclerotium rolfsii. A total of 137 fungal isolates were isolated and identified from 30 soil samples. Nine isolates solubilized inorganic phosphate (tricalcium phosphate). Eight of these isolates were isolated from the rhizosphere of Alhagi graecorum Boiss., Allium cepa L., Ehrharta calycina Sm., Ludwigia stolonifera (Guill. \& Perr.) Raven, Mentha longifolia L., Phragmites communis Trin.,Triticum aestivum $L$. and Zea mays $L$., respectively and one isolate was isolated from island's free soil. Purified single spore cultures of these nine isolates were identified to species level by multi loci DNA barcoding using internal transcribed spacer1and 2 (ITS1 and ITS 2) of the rRNA gene cluster, Calmodulin (CaM) and $\beta$-tubulin)BenA) gene markers.

Conclusions: The isolated phosphate solubilizing fungi belonged to two genera, Aspergillus and Penicillium. The phosphate solubilization index ranged from 1 to 1.5. Aspergillius japonicus 2 had the highest solubilization index (1.5) and also had the highest inhibition percentage (70\%) against Alternaria alternata. This isolate is promising for development of biocontrol agent of Fusarium solani, Geotricum candidium and Alternaria alternata. The highest phosphate solubilization by Aspergillius japonicus 2 was obtained by using sucrose as carbon source and also ammonium chloride and tryptophan as nitrogen source. The highest solubilization percentage was $78.2 \%$ at optimum glucose concentration (5\%) while the $\mathrm{pH}$ value that gave the highest solubilization percentage (90\%) was 3 . After eight days of incubation of Aspergillius japonicus 2, the solubilization percentage reached its maximum value (80.2\%).
\end{abstract}

Keywords: Biocontrol agent, $\beta$-tubulin gene markers, Calmodulin gene markers, Solubilization index

\section{Background}

Declining soil fertility in Egypt is generated due to the continuous cropping without replacing soil nutrients. The continuous application of phosphate fertilizer and soil erosions are the common problems that reduce the crop productivity. Moreover, the $\mathrm{pH}$ of Egyptian soil is

*Correspondence: Plant.Plant99@yahoo.com

Botany and Microbiology Department, Faculty of Science, Beni-Suef University, Beni-Suef, Egypt alkaline and phosphate can precipitate to form calcium phosphates which are insoluble in soil. Deficiency of soil phosphorus is the most critical factors affecting plant growth in soils. Phosphorus (P) is one of the major nutrients for crop production [1].

The inorganic phosphorus is found in the soil at $20-80 \%$ with calcium, iron and aluminum [2] and the organic form comes from the decaying living organisms [3]. Phosphorus is one of the lowest element on the earth ( $0.1 \%$ available of total) [4]. The current global 
phosphate rock could be decreased within $50-100$ years due to increasing demand and limited P mineral reserves. Phosphate solubilizing fungi are considered as renewable and potential suppliers of soluble phosphorus. They have a great advantage for plants through solubilization and mineralization [5]. Studies on phosphate solubilization by saprophytic soil fungi are still rare and a few species have been studied, with a predominance of Aspergillus sp and Penicillium sp [6]. The application of PSF to seeds or crops or soil is a promising strategy to enhance world food production without causing any environmental hazard [7]. A wide range of soil fungi are reported to solubilize insoluble phosphorus. Aspergillus niger and Penicillium funiculosum are the most dominant soil fungi capable of phosphate solubilization [8]. Elias et al. [9] isolated and characterized phosphate solubilizing fungi from different rhizosphere on solid Pikovskaya (PVK) medium. The phosphate solubilizing fungi were Aspergillus (53.69\%), Penicillium spp. (22.21\%) and Fusarium (10.58\%). Morales et al. [10] isolated phosphate solubilizing fungi from different habitats such as agricultural land, arctic region, forest and mangrove.

Gontia-Mishra et al. [11] isolated phytase producing fungi and identified them by $18 \mathrm{~S}$ rDNA sequence analysis. Panchala et al. [12] isolated and identified the phosphate solubilizing Penicillium expansum NAUGB1 based on its morphological and molecular characters. Also the effect of Penicillium expansum NAUG-B1on the growth of brinjal (Solanum melongena L.) was observed. Although, some genes were isolated and characterized from some phosphate solubilizing fungi, knowledge of the genetics of phosphate solubilization by fungi is rare and the explanation of solubilization of insoluble phosphorus at the molecular level by microorganism is inconclusive [13].

The molecular identification of PSF has not been studied in details, so it is necessary to increase our knowledge on this subject. The solubilization efficiency in presence of carbon and nitrogen sources was recorded by Pradhan and Sukla [14] who reported that glucose and maltose caused highest solubilization of phosphorus, followed by sucrose, xylose and galactose. Bhattacharya et al. [15] studied the solubilization of tricalcium phosphate by Aspergillus niger MPF-8 isolated from Muthupettai mangrove. Aspergillus niger MPF-8 showed maximum phosphate solubilization $401 \mu \mathrm{g} / \mathrm{ml}$ and $427 \mu \mathrm{g} / \mathrm{ml}$ by using glucose and ammonium sulphate supplementation.

Seshadri et al. [16] cleared that Aspergillus niger utilized mannitol as carbon and nitrate as nitrogen sources during phosphate solubilization with high efficiency.

The present study aimed to isolate, molecularly characterize and evaluate the antagonistic potential of the phosphate solubilizing fungi against some phyto-pathogenic fungi.

\section{Methods}

\subsection{Study area}

Soil samples were collected from Beni-Suef governorate as shown in Fig. $1\left(28^{\circ} 36 \mathrm{~N}-29^{\circ} 26^{\prime}\right.$ latitude and 30 $36^{\prime}$ E-31 $\left.21^{\prime} \mathrm{E}\right)$, Egypt. The climate of this region is arid, with annual rainfall of $1 \mathrm{~L} / \mathrm{m}^{2}$.

\subsubsection{Isolation and screening of P-solubilizing fungi (Qualitative method)}

Thirty soil samples were obtained from different localities and habitats as shown in Fig. 1. Soil samples were taken from rhizospheres of Alhagi graecorum Boiss., Allium cepa L., Ehrharta calycina Sm., Ludwigia stolonifera (Guill. \& Perr.) Raven, Mentha longifolia L., Phragmites communis Trin., Triticum aestivum L. and Zea mays L. Phosphate solubilizing fungi (PSF) were isolated by the dilution plate method, this method was modified by Johnson et al. [17]. $10 \mathrm{~g}$ of rhizosphere soil samples were taken at profile $(0-10 \mathrm{~cm})$ by using sterile auger and air dried for $24 \mathrm{~h}$ then passed through a $0.5 \mathrm{~mm}$ soil sieve to remove large particles. Pikovskaya medium was used in the isolation of PSF.

The compositions of the medium $(\mathrm{g} / \mathrm{l})$ are glucose, 10 g; $\mathrm{Ca}_{3}\left(\mathrm{PO}_{4}\right)_{2}, 5$ g; $\left(\mathrm{NH}_{4}\right)_{2} \mathrm{SO}_{4}, 0.5$ g; $\mathrm{NaCl}, 0.2$ g; $\mathrm{MgSO}_{4} \cdot 7 \mathrm{H}_{2} \mathrm{O}, 0.1 \mathrm{~g} ; \mathrm{KCl}, 0.2 \mathrm{~g}$; yeast extract, $0.5 \mathrm{~g}$; $\mathrm{MnSO}_{4} \cdot 7 \mathrm{H}_{2} \mathrm{O}, 0.003 \mathrm{~g} ; \mathrm{FeSO}_{4} \cdot 7 \mathrm{H}_{2} \mathrm{O}, 0.003$, agar, $15 \mathrm{~g}$ and $1000 \mathrm{ml}$ distilled water. The $\mathrm{pH}$ of the medium was adjusted to 7 before autoclaving. Rose Bengal as a bacteriostatic agent was added to the medium $(10 \mathrm{ml} / \mathrm{l})$ at concentration $1 / 15000$ [18]. One $\mathrm{ml}$ for each dilution was put in sterilized petri-dishes. Four replicates for each dilution were used. Finally, the melted PVK medium was poured in the plates containing samples. The plates were incubated at $25-28^{\circ} \mathrm{C}$ for $2-7$ days in inverted position. After incubation, fungal colonies which showed clear zones around the colonies isolated and purified.

\subsection{Purification of phosphate solubilizing fungi}

Pikovskaya,s medium without Rose Bengal addition was prepared for purification. Streak plate method was used to purify the fungal isolates. Monospore technique or hyphal tip method [19] was used to obtain monospore fungal colony. Two drops of tween 80 were added to spore suspension of pure culture of PSF. The streak plate method was used to spread the spore suspension on PDA media by sterile cotton swab. The plates were incubated at $25{ }^{\circ} \mathrm{C}$ for $24 \mathrm{~h}$. The plates were examined under light microscope to choose hyphal tip. The microscopic hyphal 


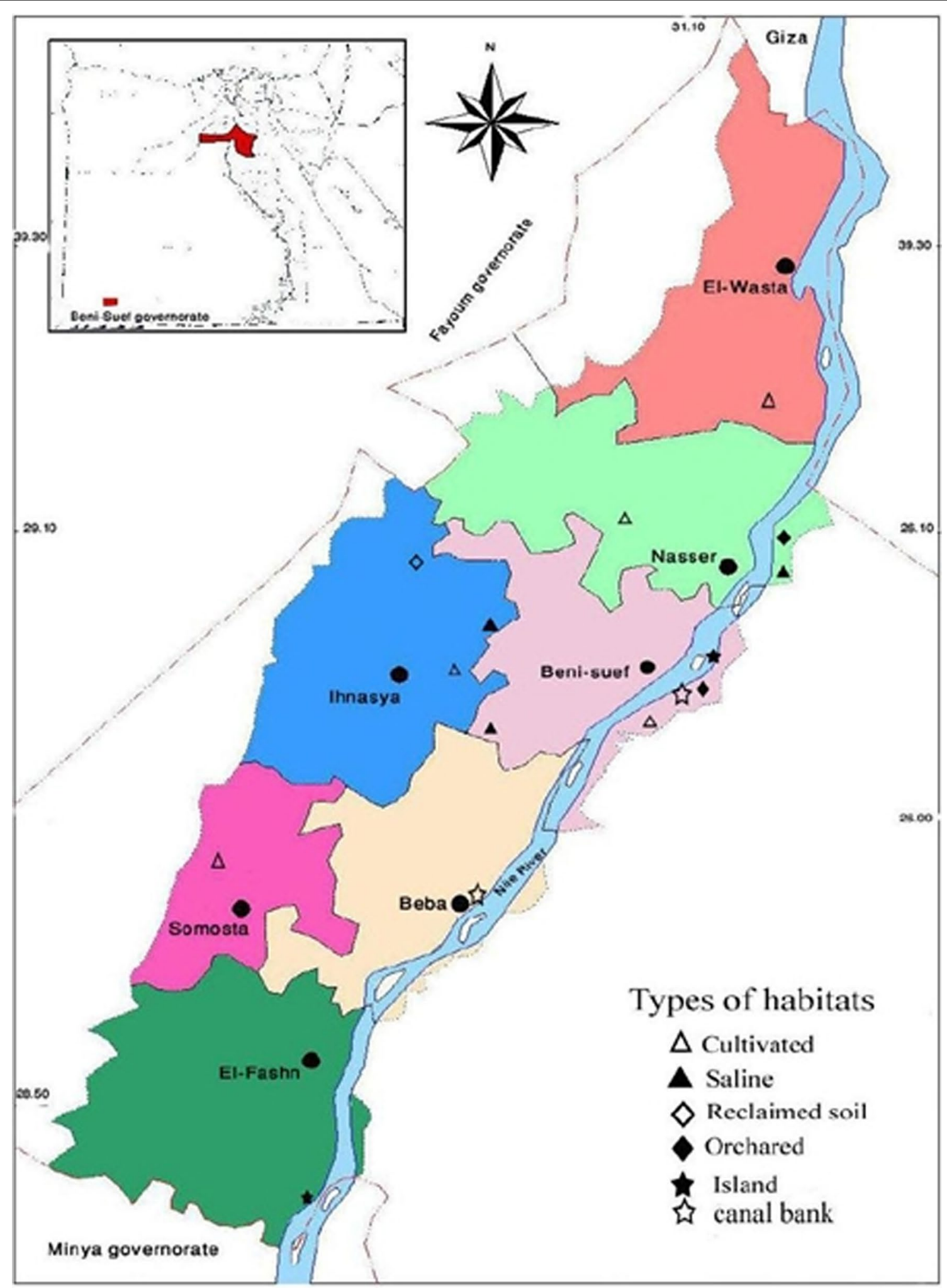

Fig. 1 A map of the study area (Beni-Suef governorate, Egypt). Black symbols refer to sampling sites in different habitats from which the soil samples were collected 


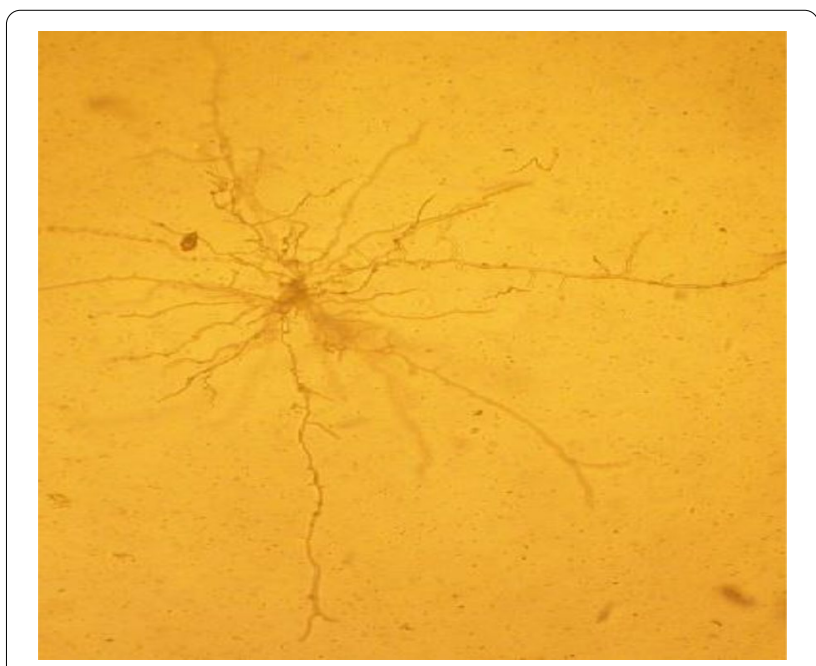

Fig. 2 Hyphal tip of Aspergillus niger under light microscope

tip as shown in Fig. 2 was cut by sterile forceps and transferred to plates containing PDA media to complete its growth. The pure cultures were preserved on Potato Dextrose Agar (PDA) slant at $4{ }^{\circ} \mathrm{C}$ for further investigation.

\subsubsection{Calculation of solubilization index of phosphate solubilizing fungi (PSF)}

The isolates were assayed for phosphate solubilization under in vitro condition by the method described by Iman [20] on Pikovskaya's agar medium. The fungal isolates were put onto the center of plates by pin point inoculation in triplicate under aseptic condition. The plates were incubated at $25-28^{\circ} \mathrm{C}$ for 7 days. The clear zone and colony diameters of the fungal isolates were measured in centimeters to determine the solubilization index. The Phosphate solubilization index was calculated by The ratio of the total diameter (colony + halo zone) and the colony diameter.

\subsubsection{Morphological identification of phosphate solubilizing fungi}

The fungal isolates were grown on Dox agar medium for 2-3 days at $25 \pm 2{ }^{\circ} \mathrm{C}$ and identified according to Moubasher [21].

\subsubsection{Extraction of genomic DNA, PCR amplification and sequencing}

The molecular identification was conducted in Microbiology and Applied Genomics Group, Institute of Chemical, Environmental \& Bioscience Engineering Vienna, University of Technology, Austria. PSF were grown on malt extract agar medium and the extraction of DNA was carried by the plant DNeasy Minikit (QIAgen $\mathrm{GmbH}$, Hilden, Germany) according to the manufacturer's instructions. The nuclear DNA region containing the ITS1 and 2 regions of the rRNA gene cluster was amplified by PCR. Secondary markers were used in addition to ITS, namely calmodulin (CaM) for genus Aspergillus and $\beta$-tubulin (BenA) for genus Penicillium. PCR products were purified with the QIAquick PCR Purification Kit (QIAgen) and were subjected to automated sequencing at MWG (Martinsried, Germany).The obtained sequences were subjected to sequence similarity comparison of the sequences from the NCBI Gene Bank database (www. ncbi.nlm.nih.gov).

2.3 Antagonistic potential of phosphate solubilizing fungi Nine PSF isolates were tested for inhibiting the growth of A. alternata, Fsolani, G. candidum, R. solani and S. rolfisii by dual culture on PDA in petri dishes according to Helrich [22]. The test pathogenic fungi were collected from Agricultural research center, Giza. The tested PSFs and fungal pathogen were separately cultured by streak plate method in PDA for 7 days. Five $\mathrm{mm}$ disc from pathogens and PSFs were grown in two polar side positions in plates of PDA. The treatments were replicated three. The dual cultures were incubated at $25-30{ }^{\circ} \mathrm{C}$ for 7 days. The diameters of colonies of both phosphate solubilizing fungi and fungal pathogens were measured after 7 days of incubation. The percentage of growth reduction of the pathogens was calculated using

$$
\% \text { growth inhibition }=\frac{R_{c}-R_{t}}{R_{c}} \times 100
$$

where $R_{c}$ is colony diameter of pathogen (control) and $R_{t}$ is colony diameter of pathogen inoculated with tested fungi.

\subsection{Effect of different carbon sources and glucose concentration on phosphate solubilization by Aspergillus japonicus 2}

The used carbon sources (1\%) were xylose, sucrose, starch and mannitol instead of glucose in PKV medium according to Jayaraman and Ilyas [23]. PKV medium was prepared without carbon source and different glucose concentrations (0-5\%) were added. Five mm diameter discs from 5 days old colony of Aspergillus japonicus 2 grown on PDA medium was inoculated to $100 \mathrm{ml}$ Pikovskya broth medium with different carbon sources and different glucose concentrations. Sterilized Pikovaskaya medium without carbon source was used as control. Culture of Aspergillus japonicus 2 was incubated at $28{ }^{\circ} \mathrm{C} \pm 2{ }^{\circ} \mathrm{C}$, for 7 days under shaking conditions (121 rpm). The culture was harvested after 7 days of incubation, centrifuged at 15,000 rpm for $10 \mathrm{~min}$ to remove the cells and debris, and then subjected to analysis. The 
solubilized phosphorus was estimated by ascorbic acid method [24].

\subsection{Effect of different nitrogen sources on the phosphate solubilization by Aspergillus japonicus 2}

The nitrogen source $(0.05 \%)$ ammonium sulphate in basel PVK medium was replaced by ammonium chloride, sodium nitrate, urea and tryptophan according to Jayaraman and Ilyas [23]. Sterilized Pikovaskaya medium without nitrogen source was used as control. Culture of A. japonicus 2 was incubated at $28{ }^{\circ} \mathrm{C} \pm 2{ }^{\circ} \mathrm{C}$, for 7 days under shaking conditions (121 rpm).The culture was harvested after 7 days of incubation, centrifuged at $15,000 \mathrm{rpm}$ for $10 \mathrm{~min}$ to remove the cells and debris and then subjected to analysis. The solubilized phosphorus was estimated by ascorbic acid method.

\subsection{Effect of different $\mathrm{pH}$ values on the solubilization activity of Aspergillus japonicus 2}

To determine the optimum $\mathrm{pH}$ for tricalcium phosphate (TCP) solubilization by A. japonicus 2, fungal discs $(5 \mathrm{~mm}$ ) from four days, old culture were inoculated into $100 \mathrm{ml}$ broth PKV medium. The initial pH of the culture medium was adjusted by adding $1 \mathrm{~N} \mathrm{HCL}$ or $1 \mathrm{~N} \mathrm{NaoH}$ solution. The different initial $\mathrm{pH}(3,4,5,6,7$ and 8). Culture of A.japonicus 2 incubated at $28^{\circ} \mathrm{C} \pm 2{ }^{\circ} \mathrm{C}$, for 7 days under shaking conditions (121 rpm) for 7 days. The solubilized phosphorus was estimated as mentioned above.

\subsection{Effect of incubation periods on the phosphate solubilization by Aspergillus japonicus 2}

The fungal discs of $A$. japonicus 2 were incubated at $28{ }^{\circ} \mathrm{C} \pm 2{ }^{\circ} \mathrm{C}$ on different time intervals $(0,2,4,6,8$ and 10 days) under shaking conditions (121 rpm) to study the effect of time on solubilization activities by $A$. japonicus 2.The culture was harvested at each time intervals and centrifuged at 15,000 rpm for $10 \mathrm{~min}$ to remove the cells and debris, and then subjected to analysis. The solubilized phosphorus was estimated as mentioned above.

\subsection{Statistical analysis}

The experiments were designed in three replicates. Statistical analysis was operated using one-way analysis of variance (ANOVA). Post-hoc mean comparison was performed by Duncan's multiple range tests at $p \leq 0.05$ by using SPSS software version 20.

\section{Results}

\subsection{Isolation, characterization and selection of phosphate solubilizing fungi (PSF)}

In this study, a total of 137 fungal isolates were obtained from 30 rhizosphere soil samples cultivated with different plants, Alhagi graecorum Boiss, Allium cepa L, Ehrharta calycina Sm, Mentha longifolia L, Phragmites communis Trin, Triticum aestivum $\mathrm{L}$ and Zea mays $\mathrm{L}$ as shown in Table 1. Out of the isolated fungi, a total of 9 phosphate solubilizing fungal cultures having potential of phosphate solubilization were isolated (Table 1). All the isolated PSF belonged to Aspergillus and Penicillium genera. Total counts of the isolates ranged from 0.03 to 2.5 colonies/ mg dry soil with percentage of $0.02-1.8 \%$. These results were observed for $P$. variabile and $P$. expansum respectively. The phosphate solubilization index of the isolates were shown in Table 1. The solubilization index (SI) of $A$. niger, $A$. carbonaceous, $A$. japonicus $3, P$. expansum and P. purpurgenum was 1 while SI of $A$. japonicus 2 was 1.5 .

Table 1 Total number of PSF isolated from rhizosphere soils (9 samples) of different plants grown in Beni-Suef governorate at different localities

\begin{tabular}{|c|c|c|c|c|c|c|}
\hline Fungal isolates & Source of isolation & $\begin{array}{l}\text { Total count } \\
\text { (colonies/mg dry } \\
\text { soil) }\end{array}$ & $\begin{array}{l}\text { Percentage of } \\
\text { PSF isolates }\end{array}$ & $\begin{array}{l}\text { Colony } \\
\text { diameters } \\
(\mathrm{cm})\end{array}$ & Clear zone $(\mathrm{cm})$ & I \\
\hline Aspergillus carbonaceous & Phragmites communis Trin & $0.10 \pm 0.01$ & 0.1 & $3 \pm 0.3$ & $3.2 \pm 0.30$ & 1.0 \\
\hline A. japonicus2 & Alhagi graecorum Boiss & $0.53 \pm 0.02$ & 0.36 & $1.2 \pm 0.12$ & $1.6 \pm 0.13$ & 1.3 \\
\hline A. japonicus2 & Zea mays L. & $0.67 \pm 0.06$ & 0.5 & $1.2 \pm 0.12$ & $1.8 \pm 0.00$ & 1.5 \\
\hline A. japonicus3 & Mentha longifolia L. & $0.2 \pm 0.02$ & 0.1 & $1.7 \pm 0.15$ & $1.7 \pm 0.17$ & 1.0 \\
\hline A.niger & Allium cepa L. & $0.5 \pm 0.01$ & 0.4 & $2.8 \pm 0.25$ & $3 \pm 0.28$ & 1.1 \\
\hline Penicillium expansum & Free soil & $2.5 \pm 0.06$ & 1.8 & $2 \pm 0.20$ & $2 \pm 0.00$ & 1.0 \\
\hline P. funiculosum & Triticum aestivum L. & $1 \pm 0.03$ & 0.7 & $1.5 \pm 0.00$ & $1.8 \pm 0.28$ & 1.2 \\
\hline P.purpurgenum & Ehrharta calycina Sm & $1.30 \pm 0.10$ & 0.9 & $2 \pm 0.2$ & $2 \pm 0.00$ & 1.0 \\
\hline p. variabile & Tamarix nilotica (Ehrenb.) Bunge & $0.03 \pm 0.01$ & 0.02 & $1.5 \pm 0.00$ & $2 \pm 0.20$ & 1.3 \\
\hline
\end{tabular}

Each value in the table is mean of three replicates \pm standard errors

$\mathrm{SI}$ is abbreviation of solubilization index 


\subsection{Molecular identification of phosphate solubilizing fungi}

Nine fungal isolates were selected to be identified using calmodulin (CaM) for genus Aspergillus and $\beta$-tubulin (Ben A) for genus Penicillium. These isolates were identified morphologically and molecularly but the result of blasting from NCBI cleared that nine isolates showed similarity between the isolates to be five isolates as shown in Table 2. The molecular method confirmed that the isolate to be $A$. niger and $A$. tubingensis with $100 \%$ and $99.4 \%$ respectively identity to $18 \mathrm{~S}$ rRNA gene sequences of $A$. niger and $A$. tubingensis in NCBI database. The accession numbers for $A$. niger and $A$. tubingensis are EF661154.1 and EF661151.1 respectively. The identification and accession numbers in Gene Bank according to blast were represented in Table 2. The sequences of $P$. chrysogenum and Talaromyces muroii were submitted in NCBI Gene Bank under accession number AY495981.1and KJ865727.1 with similarity $98 \%$ and $94 \%$ respectively. Talaromyces cellulolyticus was submitted in NCBI Gene Bank under accession number AB773823.1with similarity 93\%.

\subsection{The antagonistic activity of PSF against fungal pathogen}

A. japonicus 2 had the highest percentage of inhibition against F. solani (65\%), G. candidum (52\%) and A. alternata (70\%) as shown in Fig. 3. On the other hand, A. japonicus 2 had low ability to suppress the growth of R. solani (16\%) and S. rolfsii (19\%) as shown in Table 3. P. purpurogenum showed inhibition percentage of $68 \%$ against $A$. alternata. On the other hand, P.purpurogenum showed no inhibition percentage against S. rolfisii. $P$. funiculosum cleared inhibition percentage (19 and 35\%) against F.solani and S. rolfisii, respectively.

\subsection{Effect of carbon sources and glucose concentrations on content of solubilized P by Aspergillus japonicus 2}

The results in Fig. 4 revealed that mannitol was the poorest carbon source for phosphate solubilization by A. japonicus 2. In contrast, no significant difference in phosphate solubilzation was observed among the remaining carbon sources. The solubilization of tricalcium phosphate in presence of mannitol as carbon sources didn't show significant change when compared with control (absence of carbon source) but the other carbon sources showed significant difference compared with control.

The results in Fig. 5 showed gradually increase in soluble $\mathrm{P}$ by $A$. japonicus 2 with increasing the glucose concentration. There was visible increase in soluble $\mathrm{P}$ by increasing glucose concentration from 0 to $2 \%$ and after that the percentage of soluble P became constant at glucose concentration of 3 and $4 \%$. Finally, the percentage of soluble $\mathrm{P}$ increased (78.1\%) at $5 \%$ glucose concentration.

\subsection{Effect of nitrogen sources on content of solubilized P by Aspergillus japonicus2}

The results in Fig. 6 cleared that ammonium chloride and tryptophan were the best nitrogen sources utilized by Aspergillus japonicus 2 to solubilize the tricalcium phosphate. The percentage of solubilized phosphorus was 77.8 and $75.25 \%$ in presence of ammonium chloride and tryptophan, respectively. Aspergillus japonicus 2 revealed the lowest solubilization activity $(69.3 \%)$ in the presence of sodium nitrate.

\subsection{Effect of $\mathrm{pH}$ values on phosphate solubilization by Aspergillus Japonicus 2}

The results in Fig. 7 cleared that the lower $\mathrm{pH}$ of the medium, the higher phosphate solubilized percentage. The initial $\mathrm{pH}$ had significant effects on tricalcium phosphate solubilization. The maximum content of soluble $\mathrm{P}$ released by $A$. japonicus 2 was $90 \%$ at initial $\mathrm{pH} 3$ while the minimum content of soluble $\mathrm{P}$ was $45.6 \%$ at initial $\mathrm{pH} 8$.

\subsection{Effect of incubation time on phosphate solubilization by Aspergillus japonicus 2}

The decrease in solubilized $P$ percentage at the beginning of experiment is clear in Fig. 8 and the P concentration reached to maximum by the fungus after 8 days

Table 2 Identity (\%) of Aspergillus and Penicillium isolated in this study and most similar NCBI gene bank accession number

\begin{tabular}{|c|c|c|c|c|}
\hline & Isolates number (TUCIM) & Species identification & Identity (\%) & $\begin{array}{l}\text { Most similar gene } \\
\text { bank accession } \\
\text { number }\end{array}$ \\
\hline \multirow[t]{4}{*}{$\beta$-tubulin gene } & 6574 & Talaromyces muroii & 94 & $\underline{\mathrm{KJ} 865727.1}$ \\
\hline & 6576 & Penicillium chrysogenum & 98 & AY495981.1 \\
\hline & 6577 & Talaromyces cellulolyticus & 93 & $\underline{A B 773823.1}$ \\
\hline & 6580 & Aspergillus tubingensis & 99.4 & EF661151.1 \\
\hline Calmodulin gene & 6581 & Aspergillus niger & 100 & EF661154.1 \\
\hline
\end{tabular}

TUCIM (Collection of Industrially Important Microorganisms, Vienna University of Technology)

Underline indicates Identity (\%) of Aspergillus and Penicillium isolated in this study and most similar NCBI gene bank accession number 

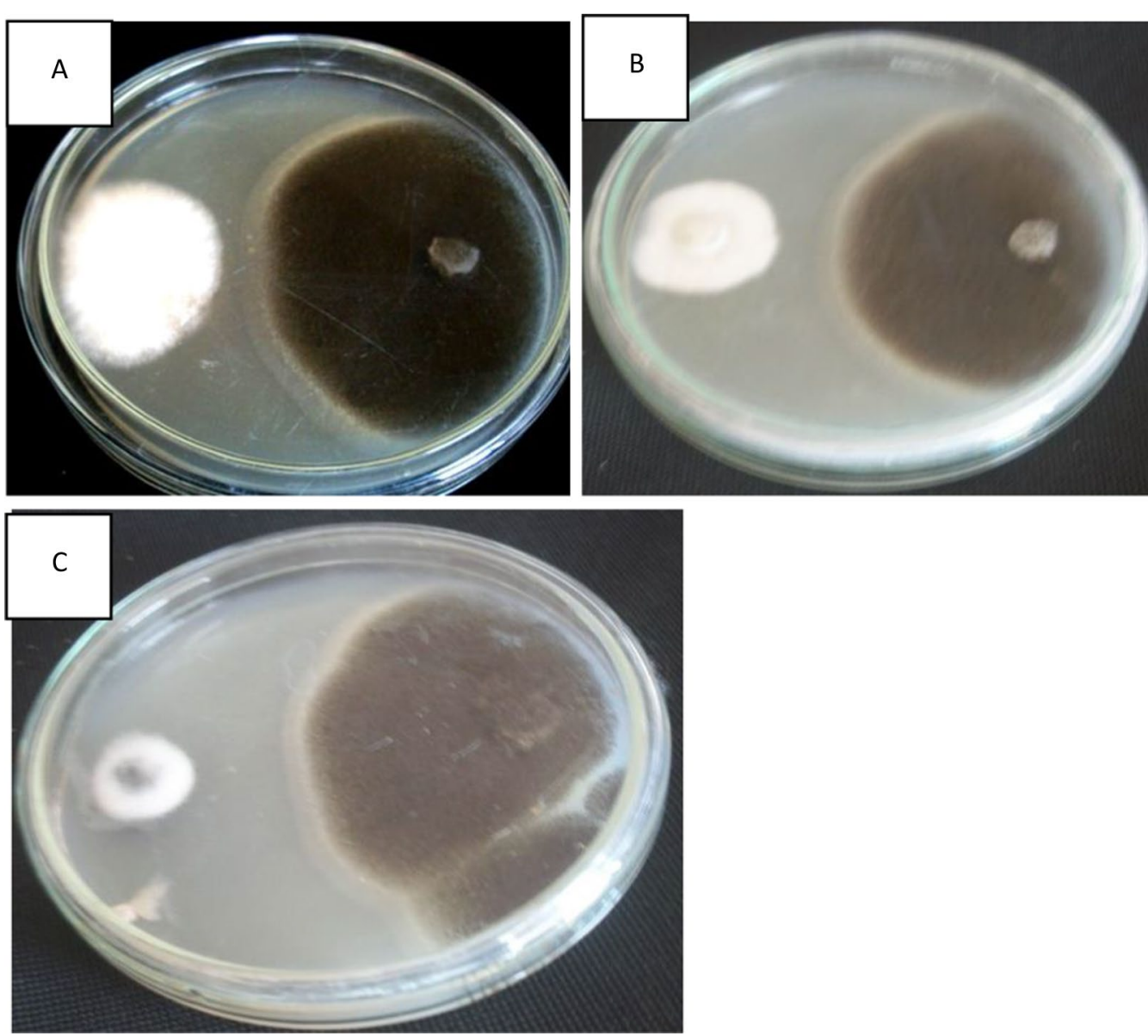

Fig. 3 Antagonistic potential of A. japonicus 2 against a F. solani, b G. candidum and c A. alternata

Table 3 Antagonistic potential of phosphate solubilizing fungi evaluated as percentage of growth inhibition of fungal pathogens

\begin{tabular}{|c|c|c|c|c|c|}
\hline Fungal isolates & A. alternata & F. solani & G.candidum & R. solani & S. rolfsii \\
\hline Aspergillus carbonaceous & $65.8 \pm 0.8$ & $65 \pm 2.8$ & $50.7 \pm 0.7$ & $14.8 \pm 1.4$ & $31 \pm 1.1$ \\
\hline A. japonicus1 & $30.4 \pm 1.4$ & $16.3 \pm 2.0$ & $51.5 \pm 0.7$ & $19.7 \pm 2.11$ & $9.8 \pm 1.8$ \\
\hline A. japonicus2 & $70.4 \pm 2$ & $65.3 \pm 3.1$ & $52 \pm 2$ & $16.2 \pm 0.2$ & $19.6 \pm 2$ \\
\hline A. japonicus3 & $68.0 \pm 2.7$ & $58.2 \pm 1$ & $27.6 \pm 1.4$ & $17.3 \pm 1.3$ & $16.7 \pm 1.8$ \\
\hline A. niger & $30.8 \pm 2.3$ & $22.2 \pm 2.8$ & $49.2 \pm 0.8$ & $7.3 \pm 1.3$ & $3.5 \pm 0.7$ \\
\hline Penicillium expansum & $30.3 \pm 1.3$ & $4 \pm 2.3$ & $4.6 \pm 2.6$ & $16 \pm 2.1$ & $0 \pm 0.0$ \\
\hline P. funiculosum & $30 \pm 2.8$ & $19 \pm 2$ & $7.5 \pm 1.5$ & $38.4 \pm 0.8$ & $35.4 \pm 1.2$ \\
\hline P.purpurgenum & $68 \pm 4.7$ & $16.3 \pm 3.5$ & $7.6 \pm 2.3$ & $20 \pm 3$ & $0.0 \pm 0.0$ \\
\hline p. variabile & $61.5 \pm 2.3$ & $17.3 \pm 1.3$ & $61 \pm 2.5$ & $50 \pm 1.3$ & $6 \pm 0.0$ \\
\hline
\end{tabular}

of incubation. The highest amount of solubilized phosphorus $(80.2 \%)$ was recorded by $A$. japonicus 2 after 8 days of incubation after that the solubilized $P$ decreased to reach $75.2 \%$ at 10 days of incubation.

\section{Discussion}

Phosphate is a nutrient that is adaptable for the growing of yields, with only $0.1 \%$ of total phosphorous in the soil 


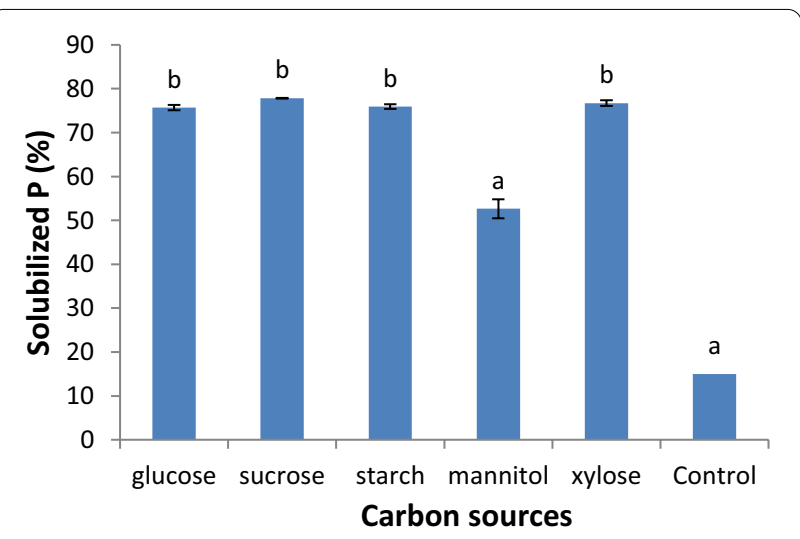

Fig. 4 Solubilization of tricalcium phosphate by A. japonicus 2 in liquid medium amended with different carbon sources. The values are means of three replicates. Means labeled with the same letter are not significantly different $(P \leq 0.05)$

available to plants [25]. PSMs able to announcement phosphorus from the soil reserves play a main role in soil fertility when $\mathrm{P}$ availability is low or $\mathrm{P}$ request is high. Most studies focus on the effect of PSB and their potential use for the enhancement of soil fertility [26]. However, insufficient filamentous fungi are also involved in phosphate solubilization, especially Aspergillus spp. and Penicillium spp. [9].

The present study cleared that the rhizosphere soils of different plants collected from Beni-Suef governorate supported different groups of P-solubilizing fungi. The most dominant species belonged to two genera, Aspergillus and Penicillium. Similarly, Chuang et al. [27], Onyia et al. [28] and Verma \& Ekka [29] isolated P-solubilizing fungi such as $A$. niger and Penicillium spp. from various rhizospheric soil samples. In the present study, Aspergillus spp. were the most frequently occurring P-solubilizing fungi which may be due to the efficiency of Aspergillus sp. in root colonization [30]. The halo zone around the colonies was considered to be indicative of phosphate-solubilization activity [31]. The percentage of PSF in this study ranged from 0.02 to $1.8 \%$. These results agree with Chen et al. [32] who reported that PSF are very few in soil constituted $0.1-0.5 \%$ of the fungal populations. The molecular methods revealed degree of similarities between nine isolates to be five isolates. So these isolates need another gene to separate between them in the future studies. Ruangsanka [33] isolated A. niger from asparagus rhizosphere which antagonized the growth of F. oxysporum with high inhibition percentage of $64 \%$. It is important to supply the plant with phosphate solubilizing fungi and at the same time it suppresses soil born plant pathogens.

A. japonicus 2 showed the highest phosphate solubilizing potential among the fungal isolates and it caused the highest growth inhibition percentage of 70 and $65 \%$ against Alternaria alternate and Fusarium solani respectively. This agrees with Khan and Khan [34,35] who studied the biocontrol effect of $A$. niger against Fusarium wilt in tomato (F. oxysporum f. sp. lycopersici; Fol). This study recommended the application of $A$. japonicus 2 which has a dual effect in the agricultural field. It solubilizes the inorganic phosphate and protected the plant against soil pathogen.

The solubilization of phosphate is not a simple phenomenon and depends on many factors, such as the nutritional, physiological and growth conditions of the cultures [36].The optimum conditions to maximize the

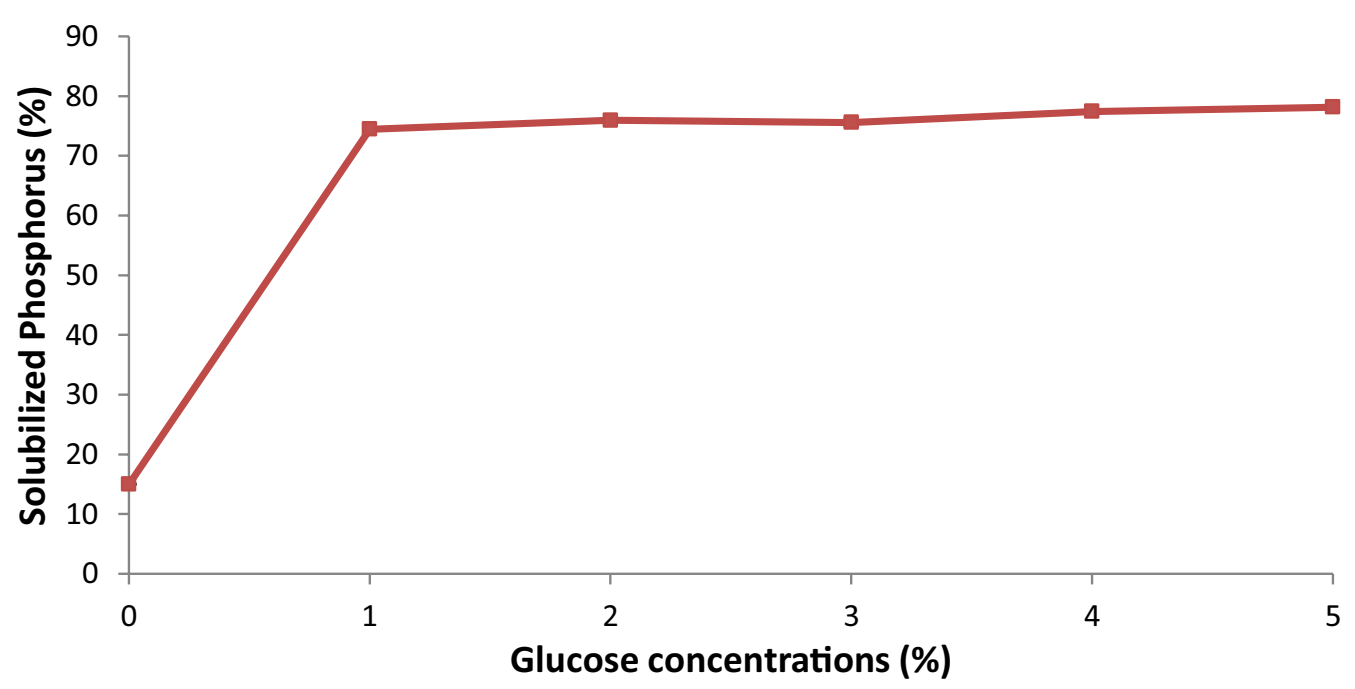

Fig. 5 Changes of phosphate solubilization by A. japonicus 2 with respect to change in glucose concentrations 


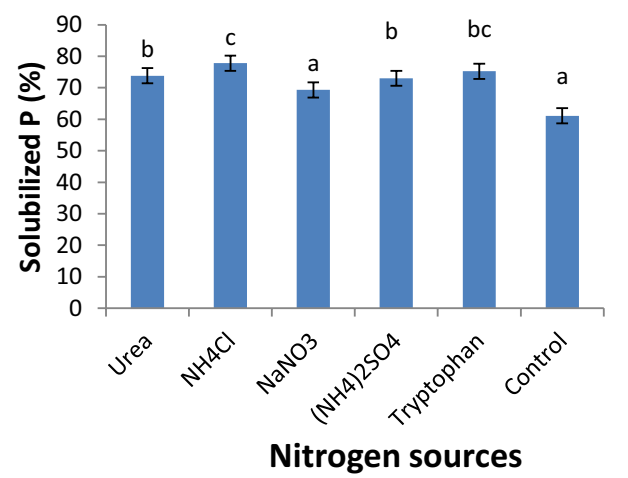

Fig. 6 Solubilization of tricalcium phosphate by A. japonicus 2 in liquid medium amended with different nitrogen sources. The values are means of three replicates. The labeled columns with the same letter are not significantly different $(P \leq 0.05)$

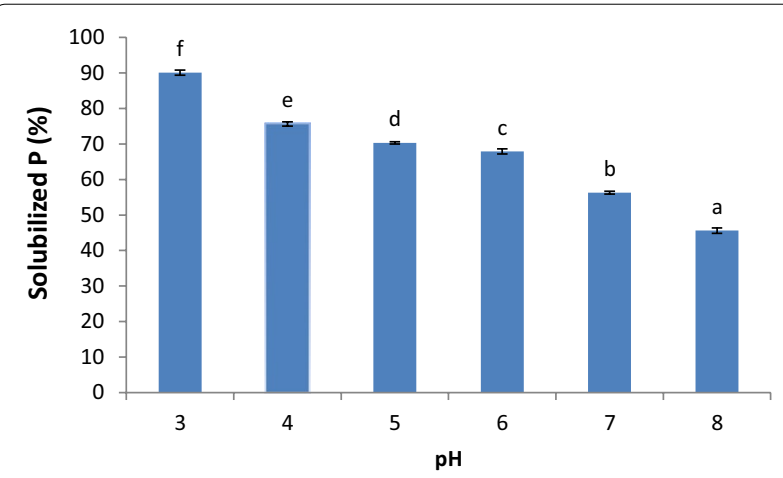

Fig. 7 Effect of different pH on phosphate solubilization by $A$. japonicus 2 in Pikovskaya's broth medium after 7 days of incubation. The labeled columns with the same letter are not significantly different $(P \leq 0.05)$

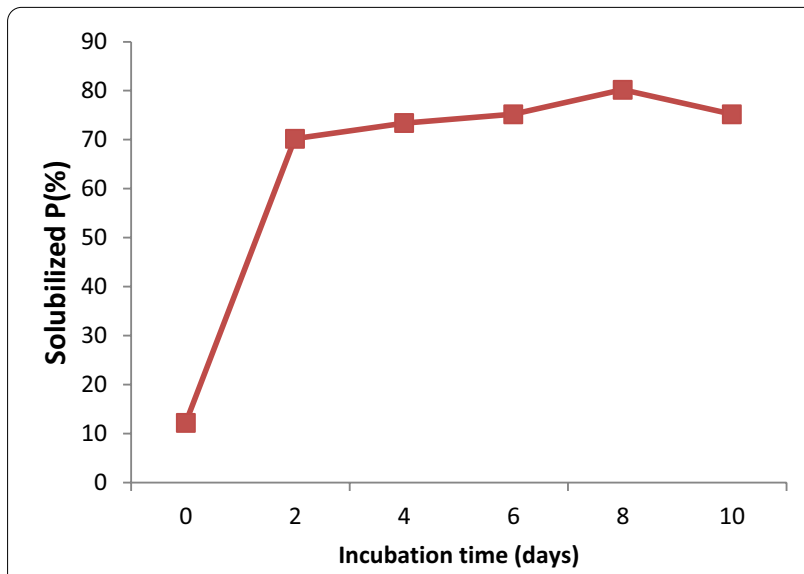

Fig. 8 Effect of incubation time on phosphate solubilization by $A$. japonicus 2 in Pikovskaya's broth medium solubilization of tricalcium phosphate by fungi were demonstrated in this paper, and results showed that the optimum conditions to solubilize tricalcium phosphate was achieved by using glucose, sucrose and xylose as carbon sources. Our results were in agreement with Bhattacharya et al. [15] who found that $A$. niger caused the highest solubilization of phosphorus when Pikovskaya broth medium amended with glucose as carbon source and ammonium sulphate as nitrogen source. A number of fungi had been reported to solubilize phosphate only in the presence of ammonium salts as nitrogen source [14]. Among the nitrogen sources used, ammonium chloride and tryptophan were found to be the best. Our study demonstrated that the optimum glucose concentration was $5 \%$ and the optimum $\mathrm{pH}$ was 3 . The increasing in the content of released phosphorus by decreasing the $\mathrm{pH}$ value confirms the organic acid theory for phosphate solubilization [37].

The time of incubation, strain of $A$. japonicus, and types of nutritive medium significantly influence the process of phosphate solubilization [38]. The above experimental results indicated the decrease in phosphorus concentration at the beginning of the experiment was due to utilization of $\mathrm{P}$ in growth and development of the organism during this period [39]. Our results agreed with Vyas et al. [40] who found increase the prolongation of incubation period from 3 to 9 days, followed by a significant decrease after 12 day of incubation.

\section{Conclusions}

A. japonicus 2 proved to be a potential phosphate solubilizing fungus. Furthermore, the ability of $A$. jabponicus 2 to convert insoluble tricalcium phosphate to soluble form was greatly enhanced by the incorporation of glucose and ammonium chloride in the medium. In addition, A. japonicus 2 inhibited the growth of Alternaria alternata, Fusarium solani and Geotrichum candidum with high efficiency. Due to its numerous beneficial effects, A. japonicus 2 strain has the potential to be established and commercially framed as a biofertilizer for field application, thus helping in increased phosphorus uptake by plants. Further studies should be done on isolation and identification of genes responsible for mineral phosphate solubilization activity by $A$. japonicus 2 .

\section{Abbreviations}

ITS1: Internal transcribed spacer1; ITS 2: Internal transcribed spacer2; PKV: Pikovskya; SI: Solubilization index; PSF: Phosphate solubilizing fungi; PSMs: Phosphate solubilizing microorganisms; PSB: Phosphate solubilizing bacteria; TUCIM: Collection of Industrially Important Microorganisms, Vienna University of Technology; NCBI: National Center for Biotechnology Information.

Acknowledgements

Not applicable. 


\section{Authors' contributions}

All authors participate with different forms to come out the research. All authors discussed the results and commented on the manuscript. Pro/ Yasser MM conceived and planned the experiment. Dr. Marzouk MA and Dr. Mousa ASM checked on the experimental work and helped in the data interpretation. Mrs. Siada H. Nasr performed the experiments, analyzed the data and wrote the manuscript. The tabulation and graphics of the data were carried out by Mrs. Siada H. Nasr.

\section{Funding}

Not applicable.

\section{Availability of data and material}

Not applicable.

\section{Declarations}

Ethical approval and consent to participate

Not applicable.

\section{Consent for Publication}

Not applicable.

\section{Competing interest}

The authors declare that they have no conflict of interest.

Received: 12 June 2021 Accepted: 11 October 2021

Published online: 28 October 2021

\section{References}

1. Reena T, Dhanya H, Deepthi MS, Pravita D (2013) Isolation of phosphate solubilizing bacteria and fungi from rhizosphere soil from banana plants and its effect on the growth of Amaranthus cruentus L. J Pharm Biol Sci 5(3):6-11

2. Richardson AE (2001) Prospects for using soil microorganisms to improve the acquisition of phosphorus by plants. Aust J Plant Physiol 28(9):897-906

3. Pandey A, Das N, Kumar B, Rinu K, Trivedi P (2008) Phosphate solubilization by Penicillium spp. isolated from soil samples of Indian Himalayan region. World J Microbiol Biotechnol 24:97-102

4. Thakur D, Kaushal R, Shyam V (2014) Phosphate solubilising microorganisms: role in phosphorus nutrition of crop plants-a review. Agric Res Commun Centre 35(3):159-171

5. Son HJ, Park GT, Cha MS, Heo MS (2006) Solubilization of insoluble inorganic phosphates by a novel salt- and $\mathrm{pH}$-tolerant Pantoea agglomerans R-42 isolated from soybean rhizosphere. Bioresour Technol 97(2):204-210

6. Ceci A, Pinzari F, Russo F, Maggi O, Persiani AM (2018) Saprotrophic soil fungi to improve phosphorus solubilization and release: in vitro abilities of several species. Ambio 47:30-40

7. Alori ET, Glick BR, Babalola OO (2017) Microbial phosphorus solubilization and its potential for use in sustainable agriculture. Front Microbiol 8:1-8

8. Yasser MM, Ahmed ASM, Osama NM, Nasr SH (2014) Solubilization of inorganic phosphate by phosphate solubilizing fungi isolated from Egyptian soils. J Biol Earth Sci 4(1):83-90

9. Elias F, Woyessa D, Muleta D (2016) Phosphate solubilization potential of rhizosphere fungi isolated from plants in Jimma Zone, Southwest Ethiopia. Int J Microbiol 2016:1-11

10. Morales H, Marín S, Ramos AJ, Sanchis V (2010) Influence of post-harvest technologies applied during cold storage of apples in Penicillium expansum growth and patulin accumulation: a review. Food Control 21(7):953-962

11. Gontia-Mishra I, Deshmukh D, Tripathi N, Bardiya-Bhurat K, Tantwai K, Tiwari S (2013) Isolation, morphological and molecular characterization of phytate-hydrolysing fungi by $18 \mathrm{~S}$ rDNA sequence analysis. Braz J Microbiol 44(1):317-323
12. Panchala BJ, Patela S, Rajkumard SJ, Mahatmac L, Singha D (2016) Isolation and identification of phosphate solubilizing Penicillium expansum NAUG$\mathrm{B} 1$ and their consequence on growth of brinjal. Ecol Environ Conserv 21:259-267

13. Rodríguez H, Fraga R, Gonzalez T, Bashan Y (2006) Genetics of phosphate solubilization and its potential applications for improving plant growthpromoting bacteria. Plant Soil 287:15-21

14. Pradhan N, Sukla LB (2006) Solubilization of inorganic phosphates by fungi isolated from agriculture soil. Afr J Biotechnol 5(10):850-854

15. Bhattacharya S, Das A, Bhardwaj S, Rajan SS (2015) Phosphate solubilizing potential of Aspergillus niger MPF-8 isolated from Muthupettai mangrove. J scient Ind Res 74(9):499-503

16. Seshadri S, Ignacimuthu S, Lakshminarasimhan C (2004) Effect of nitrogen and carbon sources on the inorganic phosphate solubilization by different Aspergillus niger strains. Chem Eng Commun 191(8):1043-1052

17. Johnson LF, Curl EA, Bond JH, Fribourg HA (1959) Methods for studying soil microflora-plant disease relationships. Burgess Publishing Company, Minneapolis

18. Smith NR, Dawson VT (1944) The bacteriostatic action of rose bengal in media used for plate counts of soil fungi. Soil Sci 58(6):467-471

19. Tuite J (1969) Plant pathological methods: fungi and bacteria. In: Kramer CL (ed) Mycologia 62(6): p 1215

20. Iman M (2008) Effect of phosphate solubilizing fungi on growth and nutrient uptake of soyabean (Glycine max L.) plants. Res J Appl Sci 4:592-598

21. Moubasher H (1993) Soil fungi in Qatar and other arab countries. The Center for Scientific and Applied Research, University of Qatar, Doha

22. Helrich K (1990) Official methods of analysis of the association of official analytical chemists. Arlington: AOAC International

23. Jayaraman R, Ilyas MHM (2010) Strain improvement of phosphate solubilizing fungal strains. J Ecobiotechnol 2(5):65-70

24. Watanabe FS, Olsen SR (1965) Test of an ascorbic acid method for determining phosphorus in water and $\mathrm{NaHCO}_{3}$ extracts from soil. Soil Sci Soc AM J 29(6):677-678

25. Vessey JK, Heisinger KG (2001) Effect of Penicillium bilaii inoculation and phosphorus fertilization on root and shoot parameters of field grown pea. Can J Plant Sci 81:361-366

26. Bindraban PS, Dimkpa CO, Pandey R (2020) Exploring phosphorus fertilizers and fertilization strategies for improved human and environmental health. Biol Fertil Soils 56:299-317

27. Chuang CC, Kuo YL, Chao CC, Chao WL (2007) Solubilization of inorganic phosphates and plant growth promotion by Aspergillus niger. Biol Fertil Soils 44(2):415-416

28. Onyia CE, Anyawu CU, Ikegbunam MN (2015) Ability of fungi, isolated from nsukka peppers and garden-egg plant rhizospheres, to solubilize phosphate and tolerate cadmium. Adv Microbiol 5(7):500-506

29. Verma A, Ekka A (2015) Isolation, Screening and assessment of phosphate solubilizing efficiency of some fungal isolates of Raipur, Chhattisgarh. J Environ Sci Toxicol Food Technol 1(1):29-36

30. Nenwani V, Doshi P, Saha T, Rajkumar S (2010) Isolation and characterization of a fungal isolate for phosphate solubilization and plant growth promoting activity. J Yeast Fungal Res 1(1):9-14

31. Mehta S, Nautiyal CS (2001) An efficient method for qualitative screening of phosphate-solubilizing bacteria. Curr Microbiol 43(1):51-56

32. Chen YP, Rekha PD, Arun AB, Shen FT, Lai WA, Young CC (2006) Phosphate solubilizing bacteria from subtropical soil and their tricalcium phosphate solubilizing abilities. Appl Soil Ecol 34:33-41

33. Ruangsanka S (2014) Identification of phosphate-solubilizing fungi from the asparagus rhizosphere as antagonists of the root and crown rot pathogen Fusarium oxysporum. Sci Asia 40(1):16-20

34. Khan MR, Khan SM (2001) Biomanagement of Fusarium wilt of tomato by the soil application of certain phosphate-solubilizing microorganisms. Int J Pest Manag 47(3):227-231

35. Khan MR, Khan SM (2002) Effects of root-dip treatment with certain phosphate solubilizing microorganisms on the fusarial wilt of tomato. Bioresour Technol 85(2):213-215 
36. Cunningham JE, Kuiack C (1992) Production of citric and oxalic acids and solubilization of calcium phosphate by Penicillium bilaii. App Environ Microbiol 58(5):1451-1458

37. Nasr SH, Mousa ASM, Marzouk MA, Yasser MM (2021) Quantitative and qualitative analysis of organic acids produced by phosphate solubilizing fungi. Egypt J Bot 61(1):167-176

38. Bojinova D, Velkova R, Grancharov I, Zhelev S (1997) The bioconversion of Tunisian phosphorite using Aspergillus niger. Nutr Cycl Agroecosystems 47:227-232

39. Halder AK, Mishra AK, Chakarbarthy PK (1991) Solubilization of inorganic phosphate by Bradyrhizobium. Indian J Exp Biol 29:28-31
40. Vyas P, Rahi P, Chauhan A, Gulati A (2007) Phosphate solubilization potential and stress tolerance of Eupenicillium parvum from tea soil. Mycol Res 111:931-938

\section{Publisher's Note}

Springer Nature remains neutral with regard to jurisdictional claims in published maps and institutional affiliations.

\section{Submit your manuscript to a SpringerOpen ${ }^{\circ}$ journal and benefit from:}

- Convenient online submission

- Rigorous peer review

- Open access: articles freely available online

- High visibility within the field

Retaining the copyright to your article

Submit your next manuscript at $\boldsymbol{\nabla}$ springeropen.com 